\title{
Ovarian cyst regression with levothyroxine in ovarian hyperstimulation syndrome associated with hypothyroidism
}

\author{
Roghieh Molaei Langroudi, Fatemeh Ghazanfari Amlashi ${ }^{1}$ and \\ Mohammad Hassan Hedayati Emami ${ }^{2}$
}

Diagnostic Radiology Department, Poursina Hospital, Guilan University of Medical Sciences, Guilan, Iran, ${ }^{1}$ Guilan Endocrinology and Metabolism Research Center, Razi Hospital, Rasht, Guilan, Iran and ${ }^{2}$ Department of Endocrinology, Guilan Endocrinology and Metabolism Research Center, Razi Hospital, Rasht, Guilan, Iran
Correspondence should be addressed to

F Ghazanfari Amlashi

Email

varash.ghazanfari@gmail.com

\section{Summary}

Background: Spontaneous ovarian hyperstimulation syndrome (sOHSS) can occur following hypothyroidism.

Ultrasonography facilitates diagnosis and monitoring of this syndrome. We describe ovarian sonographic changes in a hypothyroid patient with sOHSS after treatment with levothyroxine (L-T 4 ).

Case presentation: A 15-year-old girl presented with abdominal pain and distension for a few months. On examination, she had classical features of hypothyroidism. Abdominal and pelvic ultrasound revealed enlarged ovaries with multiple thin-walled cysts and mild ascitic fluid. On follow-up, abdominal ultrasound showed significant reduction of ovary size after 6 weeks of initiation of $\mathrm{L}-\mathrm{T}_{4}$. Normal ovary size with complete regression of ovarian cysts was seen after 4 months. Conclusion: Serial ultrasound in SOHSS associated with hypothyroidism showed regression of ovarian cysts and ovarian volume after 4 months whereas in other studies, it is reported to happen in various durations, presumably according to its etiology.

\section{Learning points:}

- OHSS can rarely occur due to hypothyroidism.

- This type of OHSS can be simply treated by $\mathrm{L}_{4} \mathrm{~T}_{4}$ replacement, rather than conservative management or surgery in severe cases.

- Ultrasound follow-up shows significant regression of ovarian size and cysts within 6 weeks of initiation of L-T ${ }_{4}$.

- Ultrasound follow-up shows normal ovarian size with complete resolution of ovarian cysts 4 months after treatment.

\section{Background}

Ovarian hyperstimulation syndrome (OHSS) is usually iatrogenic and is a potentially life-threatening complication of ovulation induction. Spontaneous OHSS might occur following high levels of human chorionic gonadotropin (HCG) in normal pregnancy, hypothyroidism, or FSH receptor mutation (1). Expanding use of ultrasonography facilitates the diagnosis and monitoring of the treatment of this syndrome (2).

We have described this syndrome in a girl virgin with primary autoimmune hypothyroidism in our previous article (3); we followed her by serial abdominal ultrasound that showed normal ovary size and regression of ovarian cysts after levothyroxine $\left(\mathrm{L}-\mathrm{T}_{4}\right)$ replacement.

\footnotetext{
open 2 access 

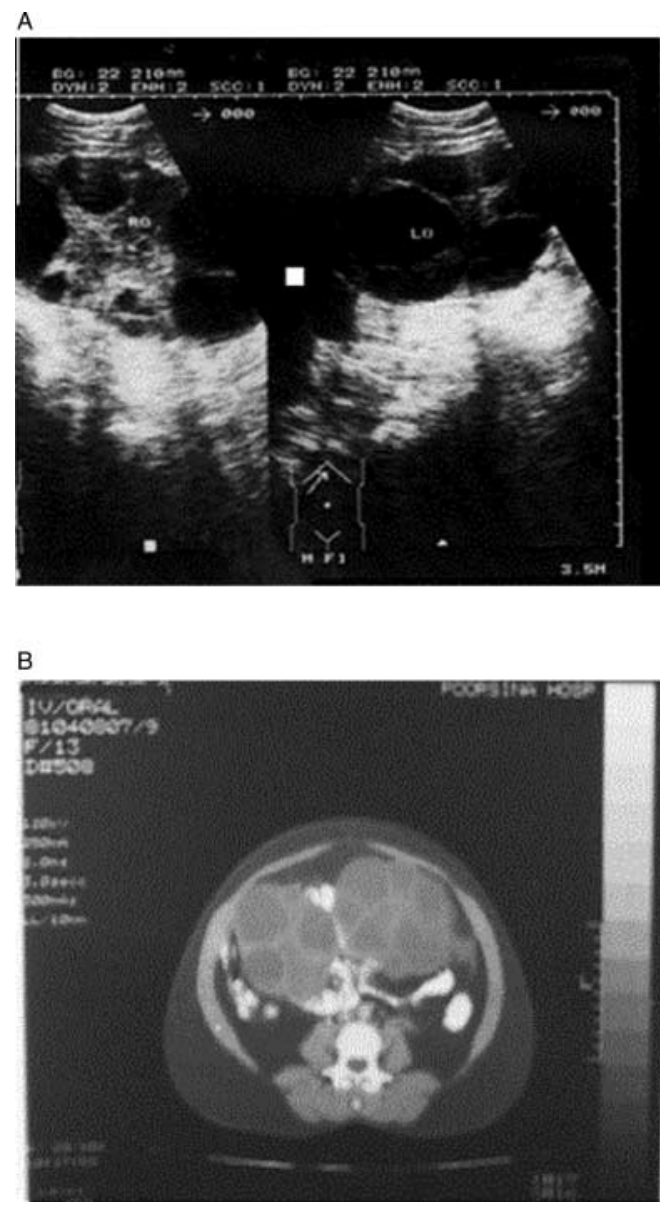

Figure 1

Imaging findings show bilateral multilobulated ovarian cysts. (A) Abdominal ultrasound and (B) abdominal CT scan (3).

\section{Case presentation}

A 15-year-old girl presented with abdominal pain and distension for a few months. On examination, she had classical features of hypothyroidism (3). The abdomen was distended and non-tender with a large palpable mass in the lower abdomen extending to the upper abdomen.

\section{Investigation}

Laboratory findings included the following: $\mathrm{Hb}=$ $11.2 \mathrm{~g} / \mathrm{dl}, \mathrm{Hct}=36.2 \%, \mathrm{MCV}=81 \mathrm{fl}, \mathrm{MCH}=28.2 \mathrm{pg}$, $\mathrm{BUN}=13 \mathrm{mg} / \mathrm{dl}, \mathrm{Cr}=0.7 \mathrm{mg} / \mathrm{dl}$, cholesterol $=290 \mathrm{mg} / \mathrm{dl}$, and $\mathrm{TG}=273 \mathrm{mg} / \mathrm{dl}$. Hormonal studies confirmed hypothyroidism: serum TSH $>100 \mathrm{mIU} / \mathrm{l}$, total $\mathrm{T}_{4}=1.8 \mu \mathrm{g} / \mathrm{dl}$ (normal: $4.4-12.5 \mu \mathrm{g} / \mathrm{dl}$, radioimmunoassay (RIA)), T3RU $=31.2 \%$ (normal: $25-34.4 \%$ ), anti-TPO antibody $=$ $290 \mathrm{U} / \mathrm{ml}$ (normal $<70$, ELISA), and prolactin $=176 \mathrm{ng} / \mathrm{ml}$
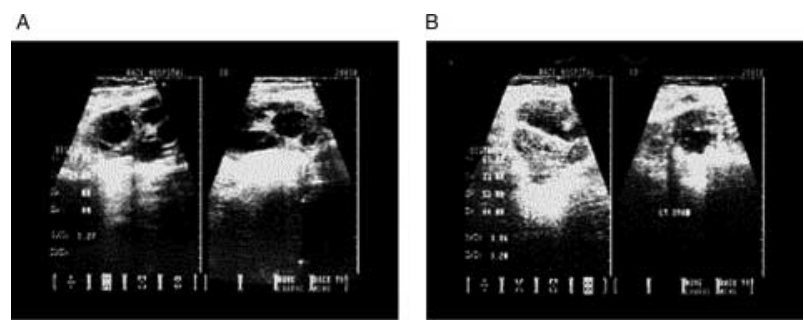

C

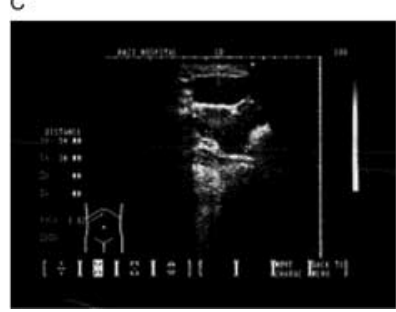

D

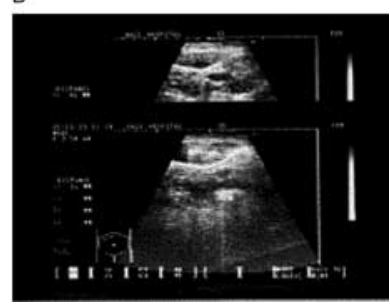

Figure 2

Follow-up abdominal sonography showed significant ovarian volume and cyst regression within 4 months of levothyroxine therapy (A) after 2 months, (B) after 4 months, (C) after 8 months (right ovary), and (D) after 8 months (left ovary).

(normal: 3-21, RIA) (3). Abdominal and pelvic ultrasound revealed enlarged ovaries that occupied the whole abdomen and pelvic cavity: right ovary, $150 \times 75 \times 62 \mathrm{~mm}$ with a volume of $454 \mathrm{cc}$; left ovary, $130 \times 70 \times 68 \mathrm{~mm}$ with a volume of $340 \mathrm{cc}$. It also represented multiple thinwalled cysts and mild ascitic fluid. Abdominal and pelvic
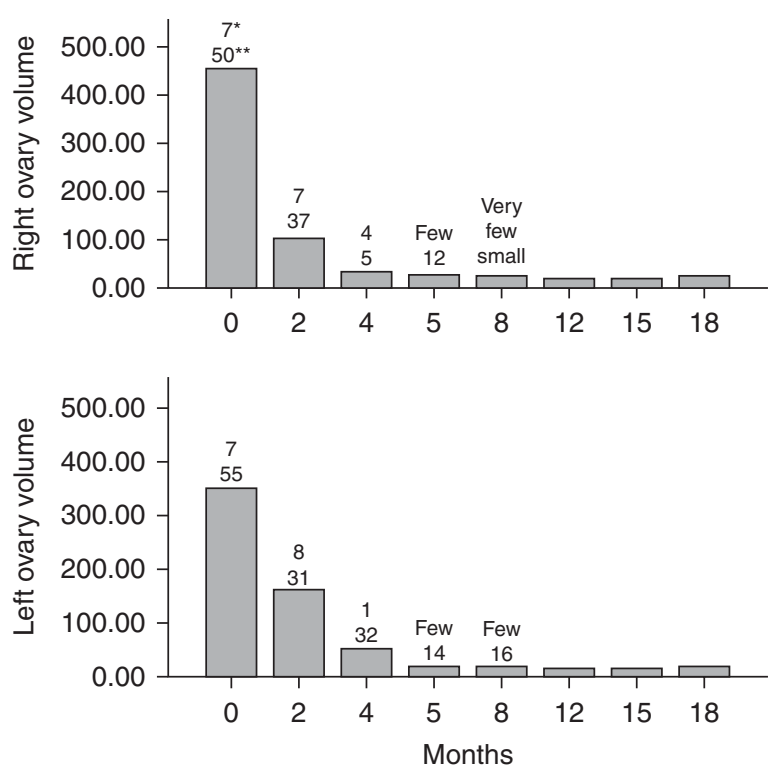

Figure 3

Right and left ovarian volume change after levothyroxine replacement. * Upper digit shows the number of cysts and **lower digit shows the largest diameter of the largest cyst. 


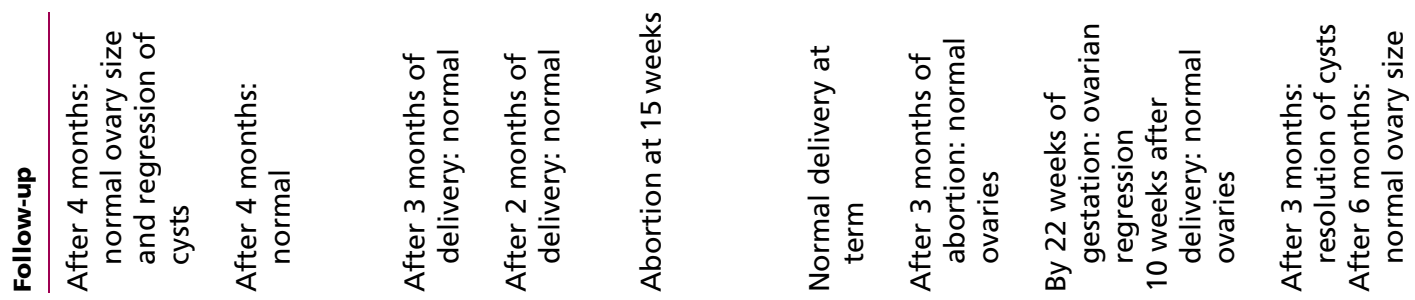
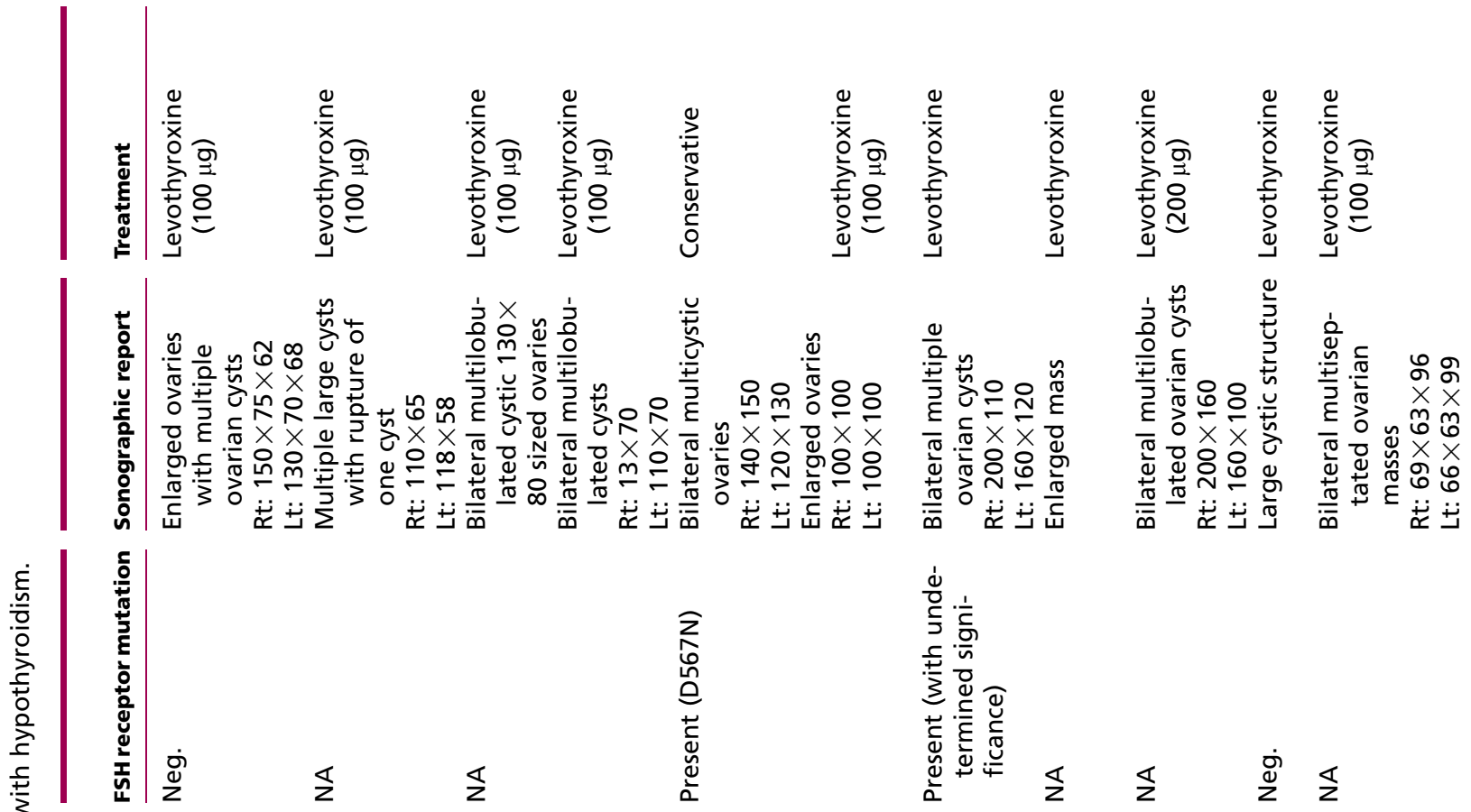

$\frac{\pi}{2} \quad \frac{\pi}{2} \quad \stackrel{s}{2} \frac{\pi}{2}$

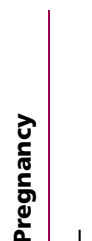

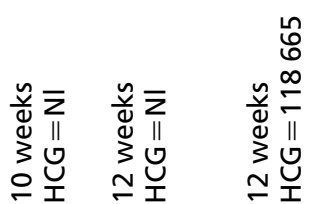
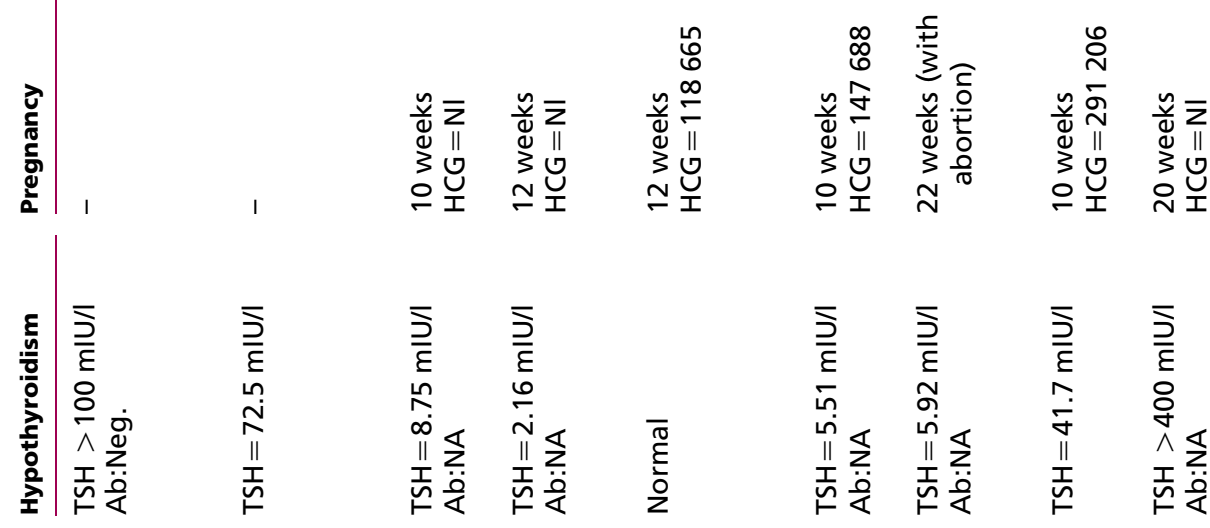

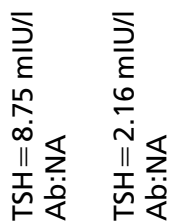

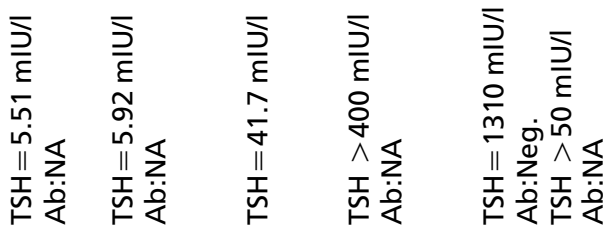

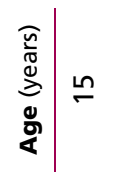

$\stackrel{\operatorname{Ln}}{+}$

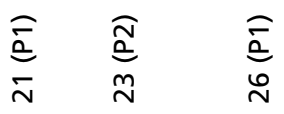

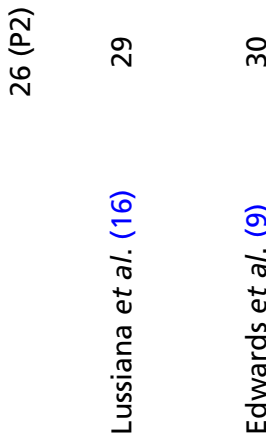

$\simeq \stackrel{\circ}{\sim}$

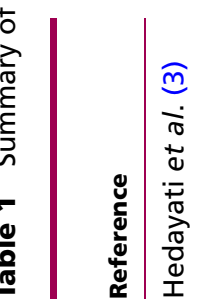

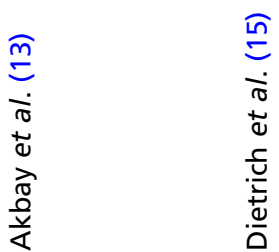

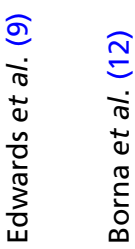

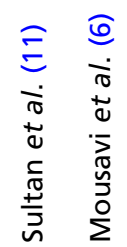


computed tomography (CT) scan showed these thin-walled cysts with no enhancement.

\section{Treatment}

She was started on $\mathrm{L}^{-\mathrm{T}_{4}} 100 \mu \mathrm{g} /$ day.

\section{Outcome and follow-up}

On follow-up ultrasound, the size of the ovaries became significantly smaller 6 weeks after $\mathrm{L}_{-} \mathrm{T}_{4}$ replacement and became normal with complete resolution of cysts after 4 months (Figs 1 and 2).

\section{Discussion}

A description of OHSS in two members of a family has recently been published (3), but there are a few studies focusing on ovarian volume and cyst regression after $\mathrm{L}-\mathrm{T}_{4}$ replacement therapy. Imaging findings in OHSS include multiple, large, and thin-walled cysts and ascitic fluid in severe forms (4). The exclusion of diagnosis of ovarian cancer is made by ultrasonography and CT scan or magnetic resonance imaging (MRI), which reveals the classical 'spoke wheel' appearance that is characteristic of theca lutein cysts without solid components. Furthermore, the reduction in ovarian volume and regression of detected cysts during close observational management and ultrasonic follow-up can differentiate OHSS from other diagnoses (5).

Here, we described resolution of ovarian cysts and normalization of the size of the ovaries in our patient 4 months after $\mathrm{L}-\mathrm{T}_{4}$ administration (Fig. 3). It is noteworthy that the kinetics of the symptoms are closely related to the life span of corpus luteum. In the absence of pregnancy, symptoms resolve spontaneously with the onset of menses, while in the presence of pregnancy, symptoms start to improve after the sixth week of pregnancy, before HCG peak (1). However, in OHSS with underlying disease such as hypothyroidism, complicated pregnancies or in the presence of mutated FSH receptor genes, the symptoms have been reported to last longer (6) (7) (8) (9) (10) (11) (12) (13) (14). Mousavi et al. (6) reported normalization of ovarian appearance in ultrasound 6 months after $\mathrm{L}_{-} \mathrm{T}_{4}$ replacement therapy. In other studies on hypothyroid patients (with and without pregnancy), considerable regression of cysts was observed after 3 months (7) (8) (9) (10) (11), with an exception that in three case reports patients experienced total regression 3 months after delivery (12) (13) (14) (Table 1). Rising serum level of 
endogenous HCG might strengthen the severity of OHSS in pregnant patients and would lead to a more complicated course than patients with hypothyroidism (15).

In conclusion, ultrasonography as well as CT scan or MRI assists the diagnosis of OHSS. By serial ultrasound, we observed regression of ovarian cysts and ovarian volume after 4 months whereas in other studies, it is reported to happen in various durations that may be related to the etiology of this syndrome.

\section{Declaration of interest}

The authors declare that there is no conflict of interest that could be perceived as prejudicing the impartiality of the research reported.

\section{Funding}

This research did not receive any specific grant from any funding agency in the public, commercial or not-for-profit sector.

\section{References}

1 Debaere A, Smits G, De Leener A, Costagliola S \& Vassart G 2005 Understanding ovarian hyperstimulation syndrome. Endocrine 26 285-289. (doi:10.1385/ENDO:26:3:285)

2 McNeary M \& Stark P 2002 Radiographic findings in ovarian hyperstimulation syndrome. Journal of Thoracic Imaging 17 230-232. (doi:10.1097/00005382-200207000-00009)

3 Hedayati Emami MH, Molaei Langroudi R \& Ghazanfari Amlashi F 2012 Ovarian hyperstimulation syndrome and autoimmune primary hypothyroidism in two members of a family. Journal of Clinical Case Reports 2 113. (doi:10.4172/2165-7920.1000113)

4 Salem SH. Abdominal, pelvic, thoracic sonography: gynecology. In Diagnostic Ultrasound, 4th edn, ch 15, pp 575-576. Eds CM Rumack, SR Wilson, JW Charboneau \& D Levine. Philadelphia: Elsevier Mosby, 2011.

5 Haimov-Kochman R, Yanai N, Yagel S, Amsalem H, Lavy Y \& Hurwitz A 2004 Spontaneous ovarian hyperstimulation syndrome and hyperreactio luteinalis are entities in continuum. Ultrasound in Obstetrics \& Gynecology 24 675-678. (doi:10.1002/uog.1759)

6 Mousavi AS, Behtash N, Hasanzadeh M, Modares Gilani M, Ghaemmaghami F, Shahroch E \& Nejad T 2005 Spontaneous ovarian hyperstimulation syndrome caused by hypothyroidism. Cancer Therapy 3 397-400.

7 Cordaso C, Olode N \& Soares L 1999 Spontaneous ovarian hyperstimulation and primary hypothyroidism with a naturally conceived pregnancy. Obstetrics and Gynecology 39 e64-e67.

8 Nappi RG, Di Naro E, D’Aries AP \& Nappi L 1998 Natural pregnancy in hypothyroid woman complicated by spontaneous ovarian hyperstimulation. American Journal of Obstetrics and Gynecology 178 610-611. (doi:10.1016/S0002-9378(98)70448-X)

9 Edwards-silva RN, Han CS, Hoang Y \& Kao LC 2008 Spontaneous ovarian hyperstimulation in a naturally conceived pregnancy with uncontrolled hypothyroidism. Obstetrics and Gynecology 111 498-501. (doi:10.1097/01.AOG.0000279139.12412.90)

10 Taher BM, Ghariabeh RA \& Jarrah NS 2004 Spontaneous ovarian hyperstimulation syndrome caused by hypothyroidism in an adult. European Journal of Obstetrics, Gynecology, and Reproductive Biology 112 107-109. (doi:10.1016/S0301-2115(03)00283-5)

11 Sultan A, Velaga MR, Fleet M \& Cheetham T 2006 Cullen's sign and massive ovarian enlargement secondary to primary hypothyroidism in a patient with a normal FSH receptor. Archives of Disease in Childhood 91 509-510. (doi:10.1136/adc.2005.088443)

12 Borna S \& Nasery A 2007 Spontaneous ovarian hyperstimulation in a pregnant woman with hypothyroidism. Fertility and Sterility 88 705.e1-705.e3. (doi:10.1016/j.fertnstert.2006.12.003)

13 Akbay E, Uzunçakmak C, Sevda Idil N, Akçiğ Z, Özel G \& Yaşar L 2010 Recurrent spontaneous ovarian hyperstimulation syndrome with hypothyroidism: a case report. Medical Journal of Bakirköy 6 42-45.

14 Michaelson-Cohen R, Altarescu G, Beller U, Reens R, Halevy-Shalem T \& Eldar-Geva T 2008 Does elevated human chorionic gonadotropin alone trigger spontaneous ovarian hyperstimulation syndrome? Fertility and Sterility 90 1869-1874. (doi:10.1016/j.fertnstert.2007.09.049)

15 Dietrich M, Bolz M, Reimer T, Costagliola S \& Gerber B 2010 Two different entities of spontaneous ovarian hyperstimulation in a woman with FSH receptor mutation. Reproductive Biomedicine Online 20 751-758. (doi:10.1016/j.rbmo.2010.02.017)

16 Lussiana C, Guani B, Restagno G, Rovei V, Menato G, Revelli A \& Massobrio M 2009 Ovarian hyper-stimulation syndrome after spontaneous conception. Gynecological Endocrinology 25 455-459. (doi:10.1080/09513590902898213)

Received in final form 6 May 2013

Accepted 15 May 2013 